\title{
Morphochemical parameters of assimilation surface of planting material Grossularia Mill depending on different backgrounds of non-root feeding
}

\author{
Natalia Mistratova $^{1^{*}}$, and Valentina Bopp $^{1}$ \\ ${ }^{1}$ Krasnoyarsk state agrarian university, Krasnoyarsk, Mira avenue, 90, Russia
}

\begin{abstract}
Gooseberry is one of the common berry crops in Siberia. But despite its merits, the gooseberry is characterized by a weak development of plant phytomass when propagated by stem cuttings, and as a result, a decrease in the quality of planting material. The results of studies of various backgrounds of non-root fertilizing showed that the variant using exogenous treatments of $\mathrm{Zn} 1 \%+\mathrm{Cu} 1 \%+6$ micronutrient elements showed an increase in the area of the leaf blade to $12.9 \mathrm{~cm}^{2}$. The accumulation level of copper, zinc, manganese and cobalt on plots using leaf fertilizing exceeded the control. Non-root feeding of $\mathrm{Zn} 1 \%+\mathrm{Cu} 1 \%$ +6 micronutrients of gooseberry when growing planting material by the green cuttings method increases the level of micronutrient accumulation $(\mathrm{Zn}, \mathrm{Co}, \mathrm{Mn})$ in the leaves and activates growth processes - contribute to the development of assimilation surface.
\end{abstract}

\section{Introduction}

Gooseberry (Grossularia Mill) is one of the most common berry crops in Siberia. Among its advantages are high productivity, excellent taste and commodity qualities of berries, valuable biochemical composition of fruits $[1,2,3]$. But despite its advantages, gooseberry are characterized by a weak development of plant phytomass when propagated by stem cuttings, and as a result, obtaining low-quality planting material, so it is necessary to look for ways to improve the technology of its propagation [4]. The purpose of the research is to determine the content of macro-and microelements in leaves and the area of the assimilation surface during the cultivation the Grossularia Mill planting material depending on different backgrounds of non-root fertilizing.

\section{Materials and methods}

The experiment was conducted in 2018-2019 at the green cuttings section of LLC «Garden Center of the Agrarian University». Cuttings were rooted in conditions of small-drop

*Corresponding author: mistratova@mail.ru 
irrigation in a greenhouse with a translucent polycarbonate fence. A mixture of peat + sand + soil (leached chernozem) in a volume ratio of 1:1:1 was used as a substrate. The planting scheme of cuttings is $5 \times 5 \mathrm{~cm}$. In 2019, rooted cuttings for harvesting were planted in open ground on the phyto section of the Department of Crop Production, Selection and Seed Production. The planting scheme is $40 \times 40 \mathrm{~cm}$. The experience is repeated three times, the placement is systematic. Variants of the experiment included nonroot treatment (spraying) with water solutions of macro-and microelements in chelated form: 1) control (water spraying); 2) $\mathrm{Zn} \mathrm{1 \%}+\mathrm{Cu} \mathrm{1 \%}+6$ trace elements (Mn- $0.018 \%$, Fe$0.02 \%$, Mo- $0.004 \%$, Co- $0.00018 \%$, B- $0.0014 \%$, Mg-0.0025\%). 3) N-1,6\% + 8 trace elements (Fe-0,4\%, Cu-0,12\%, B-0,028\%, Mn-0,36\%, Zn-0,09\%, Mg-0,05\%, Mo-0,08\%, Co- $0,016 \%$ ) - these concentrations of macro-and microelements are part of preparations prepared by manufacturers (LLC "NVP "Bashinkom"). Treatment with solutions of macroand microelements was carried out using an aerosol sprayer with a frequency of 1 time in 2 weeks. In the 1st year of research (2018), spraying was carried out 5 times, in the 2nd year (2019) 6 times. Treatment with solutions was carried out in the early morning hours - in the 1 st year of studies, when the cuttings were rooted in the green cuttings area, fine-drip watering after spraying was turned off for 1.5 hours. The object of research is the gooseberry variety - African. Green cuttings were performed according to the generally accepted method [5]. The state of the photosynthetic apparatus of the leaf is described by a number of indicators. In our research, the size of the leaf area was taken into account. The area of the leaf blade was determined for the second year of cuttings growth in open ground after the end of plant growth was completed by the pallete method [6]. Mobile forms of macro- and microelements were determined on the atomic absorption analyzer PinAAcle 900T [7] at the Research Testing Center of the FSBEI HE Krasnoyarsk State Agrarian University. Mathematical processing of the research results was performed by analysis of variance using the MS Excel computer program.

\section{Results and discussion}

The processes of growth and development in plants are closely interconnected. The term "growth" is understood, as a rule, quantitative changes that occur during development. Leaf area is a phenotypic manifestation of plant growth in the form of a growth parameter, which is formed due to the interaction of the genotype and the environmental factor [8]. The area of the assimilation surface characterizes the strength of plant growth. According to the values of this parameter, we can judge the role of treatment with solutions of $m$ cro-and microelements in changing the area of the leaf blade. Gooseberry plants in the variant using exogenous top-dressing $\mathrm{Zn} 1 \%+\mathrm{Cu} 1 \%+6$ microelements showed an increase in the area of the leaf blade- $12.9 \mathrm{~cm} 2$, which is higher than the control variant by $3.4 \mathrm{~cm} 2$, the result was statistically confirmed (SSD05=2.1) (Fig. 1).

The background of $\mathrm{N}-1.6 \%+8$ microelements contributed to a decrease in the area of assimilation surface in gooseberry plants, the indicator was lower than the control variant by $1.1 \mathrm{~cm} 2(8.4 \mathrm{~cm} 2)$ and below the variant $\mathrm{Zn} 1 \%+\mathrm{Cu} 1 \%+6$ microelements by 4,5 $\mathrm{cm} 2\left(8.4 \mathrm{~cm}^{2}\right)$, which is confirmed statistically $\left(\mathrm{SSD}_{05}=1.6\right)$.

The distribution of macro-and microelement composition of leaves differed depending on the background of non-root treatments. The level of accumulation of copper, zinc, manganese and cobalt in the variants with non-root treatments exceeded the control (table $1)$. 


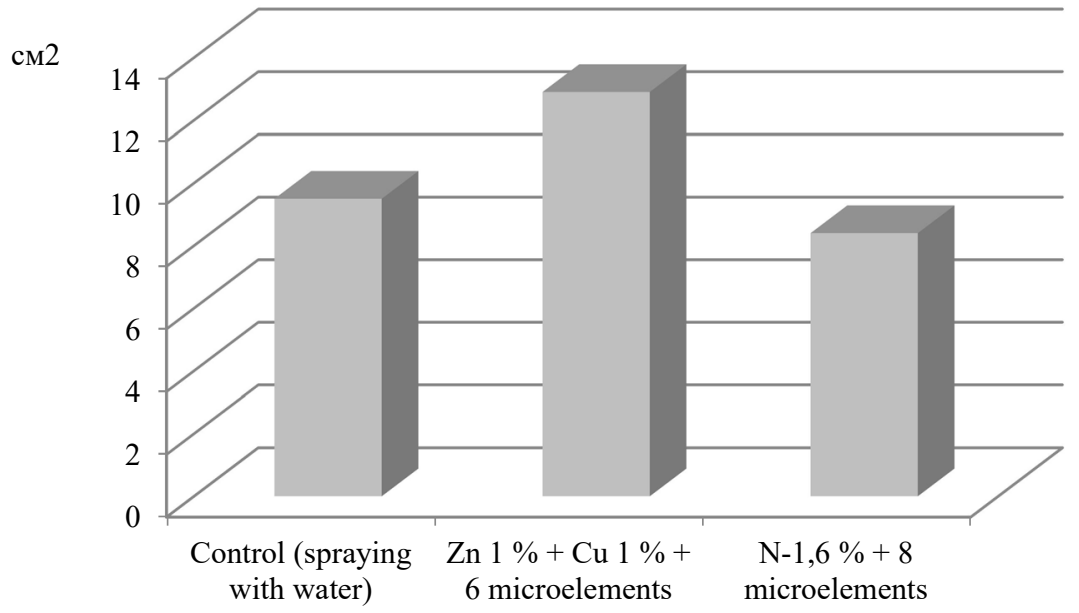

Fig. 1 - Gooseberry leaf surface area, 2019, $\mathrm{cm}^{2}$

Table 1. Influence of non-root treatments on the accumulation of mobile forms of macro-and microelements in gooseberry leaves, August, 2019

\begin{tabular}{|l|c|c|c|c|c|c|}
\hline \multirow{2}{*}{ Options } & Copper & Zinc & Iron & Cobalt & Magnesium & Manganese \\
\cline { 2 - 7 } & \multicolumn{5}{|c|}{$\mathrm{mg} / \mathrm{kg}$ dry substance } & \\
\hline $\begin{array}{l}1 . \quad \text { Control (spraying } \\
\text { with water) }\end{array}$ & 10.7 & 25.8 & 257.9 & 1.6 & 4395.0 & 114.0 \\
\hline $\begin{array}{l}2 . \quad \mathrm{Zn} \mathrm{1} \mathrm{\%} \mathrm{+} \mathrm{Cu} \mathrm{1} \mathrm{\%} \\
+6 \text { microelements }\end{array}$ & 9.6 & 26.2 & 248.9 & 2.0 & 3995.2 & 115.2 \\
\hline $\begin{array}{l}3 . \quad \mathrm{N}-1.6 \%+8 \\
\text { microelements }\end{array}$ & 11.7 & 28.2 & 227.6 & 2.0 & 3872.4 & 128.3 \\
\hline
\end{tabular}

Copper and zinc are biogenic nutrients, but in excess doses they are toxic [9]. The content of these elements in the leaves ranged from 9.6 to $11.7 \mathrm{mg} / \mathrm{kg}$, but the results were not statistically confirmed ( $\mathrm{p}>0.05)$.

The concentration in the $\mathrm{Fe}$ and $\mathrm{Mg}$ leaves on the $\mathrm{Zn}$ treatment plot of $1 \% \mathrm{Cu}$ of $1 \% 6$ microelements is lower than in the control variant, despite this, the area of the assimilation surface in this variant exceeds the control.

Cobalt has a positive effect on plant growth, participates in carbohydrate and mineral metabolism, the synthesis of chlorophyll in leaves, increases the intensity of respiration and the content of ascorbic acid in plants. Accumulation of Co in gooseberry leaves ranged from 1.6-2.0 mg/kg, on versions using non-neural feeding, the cobalt content increased to $2.0 \mathrm{mg} / \mathrm{kg}$.

The level of magnesium content on the studied backgrounds was higher in comparison with the control (115.2-128.3 mg / kg). Mg is involved in the production of energy by plant organisms, with a lack of magnesium, the root system is poorly developed.

\section{Conclusion}

As a result of research, it was found that non-root feeding of $\mathrm{Zn} 1 \%+\mathrm{Cu} 1 \%+6$ microelements of gooseberries when growing planting material by green cutting increases 
the level of micronutrient accumulation $(\mathrm{Zn}, \mathrm{Co}, \mathrm{Mn})$ in leaves and activates growth processes - contributes to the development of leaf apparatus.

\section{References}

1. N.A. Mistratova, A.A. Kolichenko, E.A. Savinich, Bul. of the Kras. St. Agr. Univ., 5, 59-65 (2018)

2. V.N. Sorokopudov, V.A. Melkumova, O.A. Sorokopudova Gooseberry in Siberia, 25 (Novosibirsk book publishing house, Novosibirsk, 1999)

3. V.L. Bopp., E.M. Kuzmina, N.A. Mistratova Fruit-growing of Siberia, 263-275 (Krasnoyarsk, KrasSAU, 2020)

4. N.A. Mistratova, D.V. Gotkin., E.V. Bryukhanov, D.S. Romanovsky, Bul. of the Bur. Agric. Acad. named after V.R. Filippov, 4, 111-117 (2019)

5. M.T. Tarasenko Green cuttings of garden and forest crops, 15-200 (Publishing house of the Moscow Agricultural Academy, Moscow, 1991)

6. V.F. Moiseichenko Methodology of experimental work in fruit growing and vegetable growing, 118-119 (Kiev, High school, 1988)

7. Guidelines for the determination of heavy metals in agricultural soils and crop products (1992)

8. T.V. Yanchuk, E.N. Sedov, Mod. Gard., 1, 12-17 (2017) Electronic journal http://journal-vniispk.ru/pdf/2017/1/3.pdf

9. L.I. Leontieva, Mod. Gard., 2, 84-93 (2018) 